\title{
Buy-back and Revenue-Sharing Contracts in Global Supply Chain
}

\author{
Yang Liu \\ School of Management and Economics, University of Electronic Science and Technology of China (China)
}

wieweit@,126.com

\section{Abstract:}

Purpose: The main propose of this study is to investigate how exchange rate risk affects the buy-back and revenue-sharing contracts in the global supply chain, hence to improve the performance of global supply chain.

Design/methodology/approach: Based on a two-echelon global supply chain, with the model equilibrium, this paper studies the difference between the buy-back contract and the revenue-sharing contract. By the transmitting of the exchange rate risk, it discusses the nodeenterprises' optimal strategies.

Findings: The result shows that: (1) Both these two contracts can diminish the inefficiency caused by demand risk, but none of them can manage the exchange rate risk. (2) No matter which currency is used to settle the payment, both these two contracts will lead to the transmitting of exchange rate risk from one node-enterprise to another. (3) When the currency of the supplier's country in the relatively appreciating, it is better to use the buy-back contract; when the currency of the supplier's country in the relatively depreciating, the revenue-sharing contract will lead to a better result.

Research limitations/implications: Though this study analyzes how the exchange rate risk affects these two contracts, it based on the assumption that node-enterprises' goal is maximizing theirs expected profit. In fact, many firms not only focus on maximizing theirs 
expected profit; the risk-taking is also an important concern. For future researches, how firms' risk-preferences affects theirs decisions in the global supply chain will be an interesting question. Also, will there be any difference if consider the node-enterprises' utility functions instead of the expected profit.

Originality/value: Existing literature about the global supply chain mainly focus on the exchange rate risk management, few of them considers the double marginalization effect caused by the demand risk. Therefore, with the exchange rate fluctuation, we discuss the difference between the buy-back contract and the revenue-sharing contract.

Keywords: global supply chain, exchange rate risk, buy-back contract, revenue-sharing contract

\section{Introduction}

The buy-back contract and the revenue-sharing contract are widely used all over the world. Evidences from different industries have confirmed both of these two contracts can achieve the same result, which is the supply chain coordination (Li, Wei \& Cai, 2012; Linh \& Hong, 2009).

As the globalization process takes shape, more and more enterprises bring the global supply chain management into their strategic planning. Both the buy-back contract and the revenuesharing contract require the transfer payments at the end of sale season. In the buy-back contract, the transfer payment is from the up-stream node-enterprise to the down-stream node-enterprise; in the revenue-sharing contract, the transfer payment is from the downstream node-enterprise to the up-stream node-enterprise. In the traditional supply chain model, the buy-back contract and the revenue-sharing contract are equivalent (Cachon, 2003). The difference between these two transfer payments will not affect the performance of supply chain, and can be diminished by parameters adjustment. In the global supply chain, the situation varies. The exchange rate fluctuation will influence these two transfer payments differently, hence to affect the performance of the global supply chain. For example, with the buy-back contract, the appreciation of the supplier's currency means the reduction of the supplier's back-buy cost; but with the revenue-sharing contract, the appreciation of the supplier's currency means the reduction of the supplier's revenue-sharing income. Therefore, how to use these two contracts in the global supply chain is becoming an important issue.

The existing literature about the buy-back contract is vast. These literatures fall broadly into 2 categories, the buy-back contract with demand uncertainty and the buy-back contract with price sensitive demand. In the demand uncertainty literature, Padmanabhan and Png (1995) discuss the return policies with a single period inventory model, and demonstrate that a manufacturer offers retailer full credit for a partial return of goods may achieve channel coordination. Padmanabhan and Png (1997) consider a supply chain model with one retailer 
and several suppliers, the results show that the buy-back contract is an effective tool to control the competition between these suppliers. Wang and Zipkin (2009) discuss the impact of agent in the buy-back contract. In the price sensitive demand literature, Emmons and Gilbert (1998) study the buy-back contract in a price sensitive market; point out that the buy-back contract can improve the performance of supply chain when the wholesale price satisfies certain conditions. Yao, Leung and Lai (2008) discuss the relationship between the degree of price sensitive and the node-enterprises' performance.

In the revenue-sharing contract literature, Mortimer (2002) studies the revenue-sharing contract in the rent industry; the results show that revenue-sharing contract can achieve the supply chain coordination. The following studies about revenue-sharing contract consider two different aspects, the revenue-sharing contract with demand uncertainty and the revenuesharing contract with random yield. In the demand uncertainty literature, Dana and Spier (2001) study the revenue-sharing contract in a demand uncertainty model; the results suggest that linear transfer payment can achieve the supply chain coordination. Giannoccaro and Pontrandolfo (2004) consider a three-level supply chain model, and also point out that revenue-sharing contract can achieve the supply chain coordination. In the random yield literature, Tang and Kouvelis (2014) consider a decentralized supply chain model; in this supply chain, both the demand and the supply are uncertain.

As we can see, most of the above studies demonstrate that these two contracts can coordinate the supply chain, but few of them focus on the difference between these two transfer payments. Also, few of them consider them in the global supply chain environment. As we mentioned before, in the global supply chain environment, exchange rate fluctuation will influence these two transfer payments differently, hence to influence the performance of the global supply chain. It is important to study the buy-back contract and the revenue-sharing contract in the global supply chain environment.

In fact, many scholars have already considered the global supply chain management. Different from the traditional supply chain, exchange rate risk plays a crucial role in the global supply chain. Based on the method of dealing with the exchange rate risk, the existing researches of the global supply chain can be divided into 3 parts, namely, the operational hedging method, financial hedging method and the contract method. The operational hedging is often used in the global supply chain network. Dasu and Li (1997) study the optimal operation polices when the supply chain facing a location problem. Huchzermeier and Cohen (1996) evaluate the supply chain's option with a dynamic programming model. Kazaz, Dada and Moskowitz (2005), consider the production-planning problem in a supply chain network model. Liu and Nagurney (2011) discuss the supply chain's offshore-outsourcing issue. These operational hedging literatures are all based on the assumption that there are different exchange-rates existing in the global supply chain. The different volatility of exchange rates can help node-enterprise build an optimal currency portfolio, hence to hedge the exchange rate risk. In the one-to-one 
global supply chain, the operational hedging method will lapse since there is only one exchange rate available. So the financial hedging method is concerned in this kind of global supply chain. Since the financial hedging is a financial topic, this literature in the global supply chain environment is relatively lacking. Caldentey and Haugh (2009) consider the flexible contract with hedging in a decentralized global supply chain. Ding, Dong and Kouvelis (2007) discusses the financial hedging and the operational hedging at the same time in a global supply chain network. Besides the hedging methods, contracts with an appropriate design can also manage the exchange rate risk. Kim and Park (2014) study the exchange rate risk sharing contract in a newsvendor model. Although these papers consider a various methods to manage exchange rate risk, but most of them neglect the demand risk, and none of them concerned the coordination of the global supply chain.

In summary, most of the buy-back contract and the revenue-sharing contract studies neglect the influence of exchange rate risk, and the global supply chain management literatures often neglect the influence of demand risk. In order to maximize the global supply chain's performance, it is important to consider the demand risk management in the global supply chain environment.

Based on this realization, this paper considers a two-echelon decartelized global supply chain with a retailer and a supplier from different countries. By studying the influence of exchange rate risk to the transfer payments, this paper discusses the difference between the buy-back contract and the revenue-sharing contract in the global supply chain environment.

The remainder of the paper is organized as follow, Section 2 presents the basic global supply chain model, in Section 3 we analyze the effects of the buy-back contract, and in Section 4 we analyze the effects of the revenue-sharing contract. Section 5 presents the numerical analysis. In Section 6, we conclude.

\section{Basic Models}

Consider a two-echelon decentralized global supply chain, this global supply chain is constituted by a retailer resides in country 1 and a supplier resides in country 2 . There is only one kind of seasonal product in this supply chain. At the beginning of the sale season, the retailer and the supplier conclude the purchase contract. After signed the contract, the supplier delivers the product to the retailer. Then the retailer sells the product in the market which located in the country 1 . In this global supply chain, since the retailer and the supplier reside in different countries, their purposes are to maximize the expected profit denominated in their own currency. In the following, no matter which contract is analyzed, their expect profits are all denominated in their own currency. 
Let $x$ denote the exchange rate, namely the price of one unit country 2's currency in the country 1's currency. At the beginning of the sale season, the value of $x$ is $x_{0}$. Since the exchange rate fluctuation, both the retailer and the supplier do not know what the exact value of $x$ will be at the end of sale season. So the retailer and the supplier forecast the value of $x$ jointly. The forecast shows that, at the end of sale season, the density of $x$ will be $g(\cdot)$, the distribution of $x$ will be $G(\cdot)$, and the expected value of $x$ will be $E$. At the end of sale season, the fluctuation range of $x$ is $x \in[A, B] . B$ is the superior limit and $A$ is the inferior limit, and satisfy $0<A \leq E$ and $B \geq E$. The greater is $B-A$, the wider fluctuation range of the exchange rate it will be.

Since the product is seasonal, we consider a newsvendor model here. Let $D$ denote the demand, the density of $D$ is $f(\cdot)$, and the distribution of $D$ is $F(\cdot)$. The fluctuation range of $D$ is $D$ $\in[0, Q]$. Based on the research of Lariviere and Porteus (2001), here we assume that $F(\cdot)$ satisfies IGFR condition. Also, we assume the demand risk and the exchange rate risk are independent. In order to demonstrate how the exchange rate fluctuation affects the contract, we do not consider the salvage and inventory in our model. The sale price $p$ is a fixed price denominated in the currency of country 1 , and the produce cost $c$ is a fixed cost denominated in the currency of country 2.

The profit of this global supply chain is all depend on the sales revenue from the country 1's market, and our research is based on a fixed sale price newsvendor model. In order to avoid the dilemma that the total profit of the global supply chain is hard to calculate, here we use the optimal order quantity to evaluate the total profit of this global supply chain. In order to evaluate the improvement of the buy-back contract and the revenue-sharing contract, we consider the decentralized process and centralized process under the wholesale price contract first.

In the decentralized decision-making model, these two node-enterprises play a Stackelberg game. Namely the supplier first announce the wholesale price $w$ denominated in currency of country 2 , then the retailer decides the order quantity $q$. Since the transfer payment at the end of sale season is not required in the wholesale contract, in order to avoid the exchange rate risk, the retailer will settle the payment right after signed the contract. For simplicity, let $S(q)$ denote the expected sale quantity, and $I(q)$ denote the expected left over. Then, $S(q)$ and $I(q)$ can be demonstrated as follows, respectively:

$$
\left\{\begin{array}{l}
S(q)=q-\int_{0}^{q} F(u) d u \\
I(q)=\int_{0}^{q} F(u) d u
\end{array}\right.
$$


Based on the Equation 1, the expected profits of both node-enterprises are given as follow:

$$
\left\{\begin{array}{l}
E\left(\Pi_{r}\right)=p S(q)-q w x_{0} \\
E\left(\Pi_{s}\right)=q(w-c)
\end{array}\right.
$$

In the equation $2, E\left(\Pi_{r}\right)$ stands for the expected profits of the retailer and denominated in the currency of country $1, E\left(\Pi_{s}\right)$ stands for the expected profits of the supplier denominated in the currency of country 2 . The retailer settle the payment immediately after the signing of the sale contract, so the exchange rate is $x_{0}$.

In the centralized decision-making model, the retailer will decide the optimal order quantity based on the product cost instead of the wholesale price. Let $q_{0}$ denote the order quantity and $E(\Pi)$ denote the total expected profit denominated in the currency of country 1 in centralized model. Therefore, the total expected profit of this global supply chain is given as follows:

$$
E(\Pi)=p S(q)-q c x_{0}
$$

In the following, we analyze how the exchange rate fluctuation affects this global supply chain. For convenience, all proofs in this paper are moved to Appendix.

Proposition 2.1: In centralized decision-making model, the optimal order quantity is $F^{-1}\left(\frac{p-c x_{0}}{p}\right)$; in decentralized decision-making model with the wholesale price contract, the optimal order quantity can be derived as follows:

$$
p \bar{F}\left(q^{*}\right)\left(1-\frac{q^{*} f\left(q^{*}\right)}{\bar{F}\left(q^{*}\right)}\right)-c x_{0}=0
$$

Based on Proposition 2.1, it is clear to see that the double marginal effect caused by the demand risk leads to a cut down in order quantity; the wholesale price contract can not coordinate this global supply chain.

\section{The Buy-back Contract in the Global Supply Chain}

Consider this global supply chain use the buy-back contract to avoid the double marginal effect caused by the demand fluctuations. Since the transfer payment at the end of the sale season is required in the buy-back contract, the fluctuation of exchange rate risk will affect this supply chain. Settling the transfer payment in the currency of country 1 will cause the supplier to suffer the exchange rate risk and vice visa. So here we will discuss these two situations separately. 
The transfer payment settled in the currency of country 1 means the buy-back price denominated in the currency of country 1 . Let $E\left(\Pi_{r b 1}\right)$ denote the expected profit of the retailer and $E\left(\Pi_{s b 1}\right)$ denote the expected profit of the supplier, then $E\left(\Pi_{r b 1}\right)$ and $E\left(\Pi_{s b 1}\right)$ is given as follows, respectively:

$$
\left\{\begin{array}{l}
E\left(\Pi_{r b 1}\right)=p S\left(q_{b 1}\right)-w_{b 1} x_{0} q_{b 1}+b_{b 1} x_{0} I\left(q_{b 1}\right) \\
E\left(\Pi_{s b 1}\right)=q_{b 1}\left(w_{b 1}-c\right)-b_{b 1} \Gamma x_{0} I\left(q_{b 1}\right)
\end{array}\right.
$$

In Equation 6, $w_{b 1}$ stands for the wholesale price denominated in the currency of country $2, b_{b 1}$ stand for the return price denominated in the currency of country 1 , and $q_{b 1}$ is the order quantity of the retailer. $\Gamma$ is the expected value of $\frac{1}{x}$, and stands for the expected price of one unit country 1's currency in the currency of country 2 at the end of the sale season. The relationship between $\Gamma, X$ and $x_{0}$ will be discussed in Lemma 1 .

Lemma 1: When the currency of country 2 in the relatively appreciating, the relationship between $\Gamma x_{0}$ and 1 depends on the distribution of exchange rate. When the currency of country 2 in the relatively depreciating, the inequation $\Gamma x_{0}>1$ holds.

Lemma 1 shows that, though there is reciprocal relation between the exchange rate retailer realized and the exchange rate supplier realized; there is no reciprocal relation between the expected exchange rate retailer realized and the expected exchange rate supplier realized. This asymmetric relation may affect the global supply chain differently.

Based on Lemma 1, we can get the proposition 3.1.

Proposition 3.1: With the buy-back contract, settle the transfer payment in the currency of country 1 will cause the order quantity diverge from the optimal order quantity of centralized decision-making model. The optimal expected profits of both node-enterprises can be written as follows, respectively:

$$
\left\{\begin{array}{l}
E\left(\Pi_{r b 1}\right)=\lambda_{b 1} \Pi_{b 1}-\frac{\left(1-\lambda_{b 1}\right) \lambda_{b 1} q_{b 1}\left(p-c x_{0}\right)\left(\Gamma x_{0}-1\right)}{\lambda_{b 1}+\left(1-\lambda_{b 1}\right) \Gamma x_{0}} \\
E\left(\Pi_{s b 1}\right)=\frac{\left(1-\lambda_{b 1}\right) \Pi_{b 1}}{x_{0}}+\frac{\left(1-\lambda_{b 1}\right)\left(\Gamma x_{0}-1\right)}{x_{0}}\left(\frac{\lambda_{b 1} q_{b 1}\left(p-c x_{0}\right)}{\lambda_{b 1}+\left(1-\lambda_{b 1}\right) \Gamma x_{0}}-p I\left(q_{b 1}\right)\right)
\end{array}\right.
$$

According to Proposition 3.1, we can directly obtain the following two corollaries.

Corollary 3.1: The optimal order quantity is lower than the optimal order quantity of centralized model when the currency of country 2 in the relatively appreciating.

Corollary 3.2: The optimal order quantity may exceed the optimal order quantity of the centralized model when the currency of country 2 in the relatively depreciating. 
Proposition 3.1 and its corollaries show that, when the transfer payment is settled in the currency of country 1 , the exchange rate risk will affect the supplier's performance inevitably. In order to avoid the impact of the exchange rate risk, the supplier will adjust the wholesale price and the buy-back price. The impact of the exchange rate risk will transmit to the retailer by this kind of price adjustment, hence to cause the changes of the optimal order quantity.

The transfer payment settled in the currency of country 2 means the buy-back price denominated in the currency of country 2. Let $E\left(\Pi_{r b 2}\right)$ denote the expected profit of the retailer and $E\left(\Pi_{s b 2}\right)$ the expected profit of the supplier, then $E\left(\Pi_{r b 2}\right)$ and $E\left(\Pi_{s b 2}\right)$ is given as follow:

$$
\left\{\begin{array}{l}
E\left(\Pi_{r b 2}\right)=p S\left(q_{b 2}\right)-w_{b 2} x_{0} q_{b 2}+b_{b 2} E I\left(q_{b 2}\right) \\
E\left(\Pi_{s b 2}\right)=q_{b 2}\left(w_{b 2}-c\right)-b_{b 2} I\left(q_{b 2}\right)
\end{array}\right.
$$

In Equation 5, $w_{b 2}$ stand for the wholesale price denominated in the currency of country $2, b_{b 2}$ stand for the return price denominated in the currency of country 2 , and $q_{b 2}$ is the order quantity of the retailer.

Proposition 3.2: With the buy-back contract, settle the transfer payment in the currency of country 2 will cause the order quantity diverge from the optimal order quantity of centralized decision-making model. The optimal expected profits of both node-enterprises can be written as follows, respectively:

$$
\left\{\begin{array}{l}
E\left(\Pi_{r b 2}\right)=\lambda_{b 2} \Pi_{b 2}+\frac{b_{b 2}\left(w_{b 2}-c\right)\left(x_{0}-E\right)}{p} x_{0} q_{b 2}-b_{b 2} I\left(q_{b 2}\right)\left(x_{0}-E\right) \\
E\left(\Pi_{s b 2}\right)=\left(1-\lambda_{b 2}\right) \frac{\Pi_{b 2}}{x_{0}}-\frac{b_{b 2}\left(w_{b 2}-c\right)\left(x_{0}-E\right) q_{b 2}}{p}
\end{array}\right.
$$

Proposition 3.2 shows that, when the transfer payment settled in the currency of country 2, the exchange rate risk will affect the retailer's performance inevitably. In order to avoid the impact of the exchange rate risk, the retailer will adjust the order quantity. The impact of the exchange rate risk will transmit to the supplier by the adjustment of order quantity.

Based on Proposition 3.1 and Proposition 3.2, it is easy to see that, the impact of the exchange rate risk will transmit form one node-enterprise to the other with the buy-back contract. No matter the transfer payment is made in what currency, the optimal order quantity always depends on the forecasts of the exchange rate's expected value at the end of sale season. As a result, the buy-back contract can not manage the exchange rate risk; it can only diminish the impact of demand risk. 


\section{The Revenue-sharing Contract in the Global Supply Chain}

With the revenue-sharing contract, the situation varies. In the revenue-sharing contract, the retailer is required to transfer a percentage of its revenue to the supplier at the end of sale season. Since the retailer's revenue is denominated in the currency of country 1 . The supplier will surely suffer from the exchange rate risk.

Let $E\left(\Pi_{r r 1}\right)$ donate the expected profit of the retailer and $E\left(\Pi_{s r 1}\right)$ donate the expected profit of the supplier. Then their expected profit can be written as follows:

$$
\left\{\begin{array}{l}
E\left(\Pi_{r r 1}\right)=p \varphi S\left(q_{r 1}\right)-q_{r 1} w_{r 1} x_{0} \\
E\left(\Pi_{s r 1}\right)=q_{r 1}\left(w_{r 1}-c\right)+p(1-\varphi) \Gamma S\left(q_{r 1}\right)
\end{array}\right.
$$

In Equation 6, $w_{r 1}$ stands for the wholesale price denominated in the currency of country 2, $\varphi$ stand for the fraction of supply chain revenue the retailer keeps, and $q_{r 1}$ is the order quantity of the retailer.

Proposition 4.1: With the revenue-sharing contract, the impact of exchange rate risk will transmit to the retailer by the adjustment of the wholesale price. The optimal expected profits of both node-enterprises can be written as follows, respectively:

$$
\left\{\begin{array}{l}
E\left(\Pi_{r r 1}\right)=\varphi \Pi_{r 1}+\frac{q_{r 1} \varphi c x_{0}(1-\varphi)\left(\Gamma x_{0}-1\right)}{1+(1-\varphi)\left(\Gamma x_{0}-1\right)} \\
E\left(\Pi_{s r 1}\right)=\frac{(1-\varphi) \Pi_{r 1}}{x_{0}}+\frac{p S\left(q_{r 1}\right)(1-\varphi)\left(\Gamma x_{0}-1\right)}{x_{0}}-\frac{q_{r 1} \varphi c(1-\varphi)\left(\Gamma x_{0}-1\right)}{1+(1-\varphi)\left(\Gamma x_{0}-1\right)}
\end{array}\right.
$$

According to Proposition 4.1, we can directly obtain the following two corollaries.

Corollary 4.1: When $\Gamma x_{0}-1>0$ holds, the exchange rate risk will cause supplier's optimal expected profit increase $\frac{p S\left(q_{r 1}\right)(1-\varphi)\left(\Gamma x_{0}-1\right)}{x_{0}}$, and the supplier will transfer $\frac{q_{r 1} \varphi c(1-\varphi)\left(\Gamma x_{0}-1\right)}{1+(1-\varphi)\left(\Gamma x_{0}-1\right)}$ expected profit to the retailer by decreasing the wholesale price.

Corollary 4.2: When $\Gamma x_{0}-1<0$ holds, the exchange rate risk will cause supplier's optimal expected profit decrease $\frac{p S\left(q_{r 1}\right)(1-\varphi)\left(\Gamma x_{0}-1\right)}{x_{0}}$, and the supplier will get $\frac{q_{r 1} \varphi c(1-\varphi)\left(\Gamma x_{0}-1\right)}{1+(1-\varphi)\left(\Gamma x_{0}-1\right)}$ expected profit from the retailer by increasing the wholesale price.

Proposition 4.1 and its corollaries indicate that, because of the revenue-sharing decisionmaking, the supplier will suffer from the exchange rate risk inevitably. In order to avoid the exchange rate risk, the supplier will transmit the exchange rate risk to the retailer by the adjustment of the wholesale price. The revenue-sharing contract can diminish the demand 
risk, but can not manage the exchange rate risk. When the currency of country 2 faces the depreciation, the revenue-sharing process will bring extra profit to the supplier compare with the situation without exchange rate risk.

It is important to note that, the expected profit of centralized decision making model is only affected by exchange rate risk, while the expected profit of decentralized decision making model is affected by exchange rate risk and demand risk. These two expected profits with the same value are not equivalent. So, we can not draw the conclusion that, with the appropriate contract, the performance of global supply chain is better than the centralized performance.

\section{Numerical Analysis}

This section analyzes the effects of exchange rate fluctuation on the buy-back contract, the revenue-sharing contract and supply chain performance. And this numerical analysis is made on the basis of Matlab7.0.

In order to illustrate the impact of the exchange rate risk, we generate a series of exchange rate risk with the different expected value and fluctuation range. These exchange rate risks all follow the normal distribution, with the expected values from 0.75 to 1.25 , and the fluctuation ranges from 0.5 to 1 . The others parameters are assigned below:

\begin{tabular}{|c|c|c|c|}
\hline$p$ & $c$ & $x_{0}$ & $D$ \\
\hline 100 & 20 & 1 & Unif $[500,1500]$ \\
\hline
\end{tabular}

Table 1. Parameters Assignment

In our figures, $E$ stands for the forecasted expected value of the exchange rate, and $B-A$ stands for the fluctuation range of the exchange rate. For simplicity, in our figures, we call the $E<1$ area as the appreciation area and $E<1$ area as the depreciation area. The optimal order quantities with different contracts are listed below. 


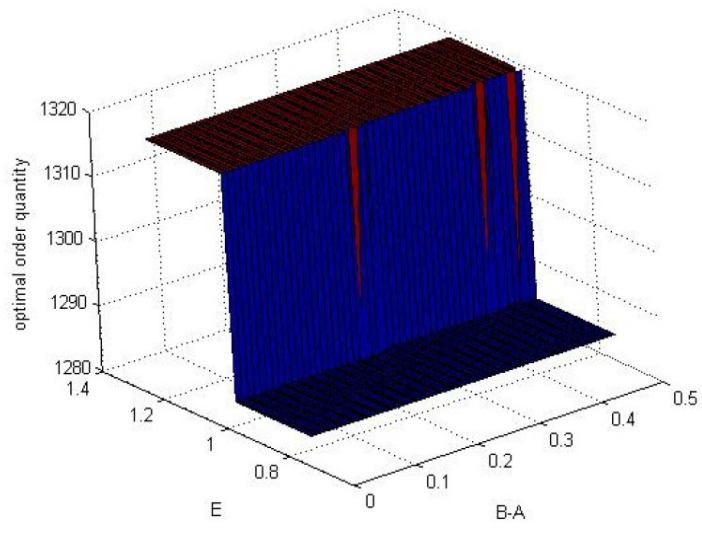

Figure 1. Optimal order quantity with buy-back contract (settle the buy-back payment in the currency of country 1)

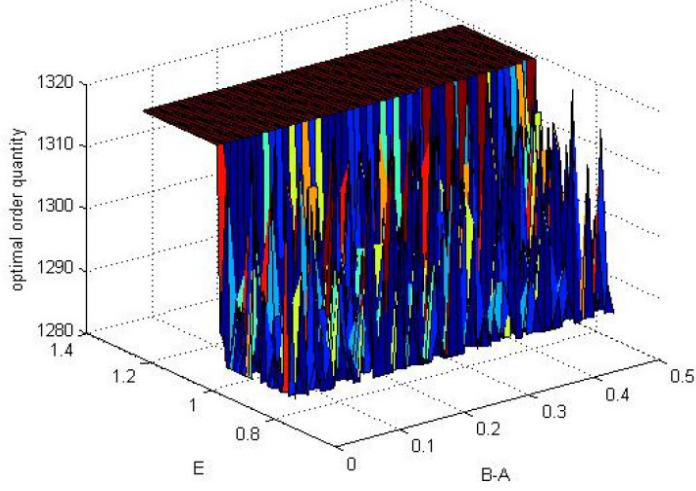

Figure 2. Optimal order quantity with buy-back contract (Settle the buy-back payment in the currency of country 2)

Figure 1 and 2 show that, when the currency of country 2 faces the appreciation, the optimal order quantity will exceed the optimal order quantity in the centralized decision-making model. This happens because the appreciation of country 2's currency will decrease the supplier's buy-back cost or increase the supplier's buy-back income. Since there is no exchange rate risk in the centralized decision-making, this appreciation will lead to a rise in the optimal order quantity is reasonable.

Since the wholesale price is settled without exchange rate fluctuation, settled the buy-back payment in the currency of country 1 means the exchange rate risk will not affect the retailer directly. Therefore, the optimal order quantities in depreciation area are relatively stable in Figure 1. But in Figure 2, settled the buy-back payment in the currency of country 2 will cause the retailer to suffer from exchange rate risk directly. Hence, the optimal order quantity fluctuates remarkably in the depreciation area. 


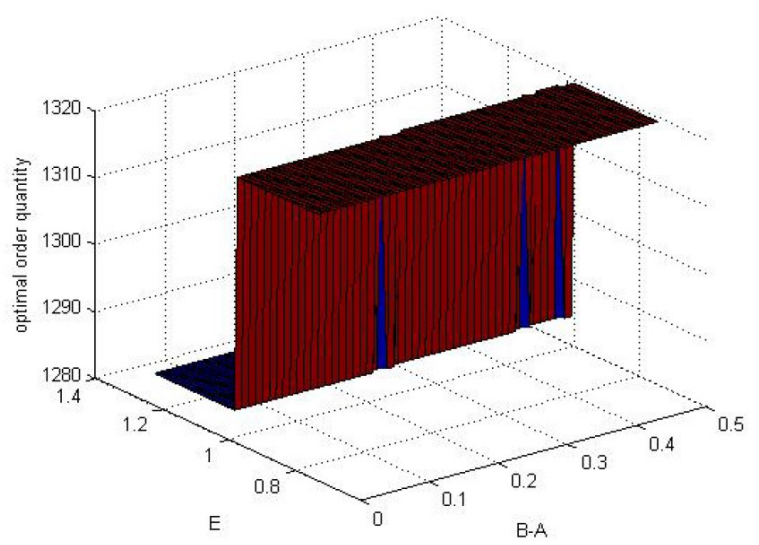

Figure 3. Optimal order quantity with revenue-sharing contract

Figure 3 illustrates the optimal order quantity with the buy-back contract. Contrary to Figure 1 and 2, the optimal order quantity is higher in the appreciation area and lower in the depreciation area. This happens because the appreciation of country 2's currency will decrease the supplier's revenue sharing income. Since the supplier's goal is to maximize the expected profit denominated in the currency of its own country, the appreciation of country 2's currency will surely damage the supplier's interests.

Figure 1, 2 and 3 show that, the fluctuation range of the exchange rate risk has small influence on the optimal order quantity. The reason is simple, that is, the order quantity is decided all by the retailer based on the excepted profit but not the volatility of the exchange rate. Also Figure 2 shows that the fluctuation range of the exchange rate has limited influence on the optimal order quantity when the retailer suffers from the exchange rate directly.

In order to illustrate the different between the these contracts, we compare the difference between the optimal order quantities in the circumstance of $B-A=0.25$, namely the medium sized fluctuation range. From Figure 4, it is clearly to see that the buy-back contract and the revenue-sharing contract will influence the global supply chain differently with the different forecasts of the exchange rate's expected value at the end of the sale season. 


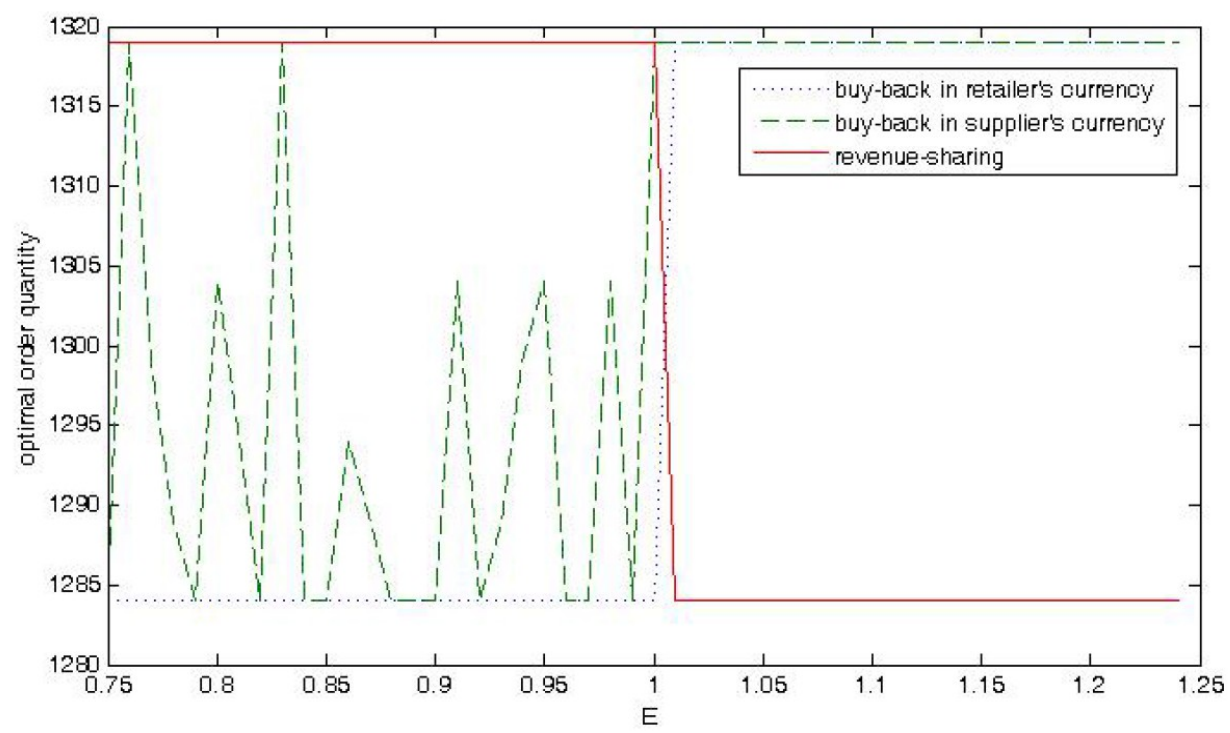

Figure 4. The revenue-sharing contract versus buy-back contract

\section{Conclusion}

In the global supply chain, the exchange rate fluctuation is the factor that cannot be avoided. We studied the buy-back contract and the revenue-sharing contract in a decentralized global supply chain, analyzed the impacts of exchange rate fluctuation on the buy-back contract and the revenue-sharing contract. Based on our research, we can draw the following conclusions. Though both the buy-back contract and the revenue-sharing contract can diminish the demand risk, the differences in transfer payment lead to a different performance in the global supply chain. The settlement of transfer payment will lead to a transmitting of the exchange rate risk form one node-enterprise to another. The tendency of exchange rate risk will also influence the efficiency of these two contracts. When the currency of the supplier's country faces the appreciation, it is better to use the buy-back contract; when the currency of the supplier's country faces the depreciation, the revenue-sharing contract will lead to a better result.

So far, there are few studies on the coordination contracts in the global supply chain, and the coordination studies are even rarer. In the future research, there are several interesting extensions. First, in the global supply chain, most of the existing literature only concerned one kind of risk. In order to maximize the performance of global supply chain, how to manage different risks simultaneously is a crucial issue. How to evaluate the total profit of the global supply chain is also an important question. Since node-enterprises often use different currencies, the appropriate evaluation of global supply chain's total profit is the precondition for global supply chain coordination. 


\section{References}

Cachon, G.P. (2003). Supply chain coordination with contracts. Handbooks in operations research and management science, 11, 227-339. http://dx.doi.org/10.1016/S0927-0507(03)11006-7

Caldentey, R., \& Haugh, M.B. (2009). Supply contracts with financial hedging. Operations Research, 57(1), 47-65. http://dx.doi.org/10.1287/opre.1080.0521

Dana Jr, J.D., \& Spier, K.E. (2001). Revenue sharing and vertical control in the video rental industry. The Journal of Industrial Economics, 49(3), 223-245. http://dx.doi.org/10.1111/14676451.00147

Dasu, S., \& Li, L. (1997). Optimal operating policies in the presence of exchange rate variability. Management Science, 43(5), 705-722. http://dx.doi.org/10.1287/mnsc.43.5.705

Ding, Q., Dong, L., \& Kouvelis, P. (2007). On the integration of production and financial hedging decisions in global markets. Operations Research, 55(3), 470-489. http://dx.doi.org/10.1287/opre.1070.0364

Emmons, H., \& Gilbert, S.M. (1998). Note. The role of returns policies in pricing and inventory decisions for catalogue goods. Management science, 44(2), 276-283. http://dx.doi.org/10.1287/mnsc.44.2.276

Giannoccaro, I., \& Pontrandolfo, P. (2004). Supply chain coordination by revenue sharing contracts. International journal of production economics, 89(2), 131-139. http://dx.doi.org/10.1016/j.ijpe.2004.10.006

Huchzermeier, A., \& Cohen, M.A. (1996). Valuing operational flexibility under exchange rate risk. Operations research, 44(1), 100-113. http://dx.doi.org/10.1287/opre.44.1.100

Kazaz, B., Dada, M., \& Moskowitz, H. (2005). Global production planning under exchange-rate uncertainty. Management Science, 51(7), 1101-1119. http://dx.doi.org/10.1287/mnsc. 1050.0384

Kim, K.K., \& Park, K.S. (2014). Transferring and sharing exchange-rate risk in a risk-averse supply chain of a multinational firm. European Journal of Operational Research, 237(2), 634-648. http://dx.doi.org/10.1016/j.ejor.2014.01.067

Lariviere, M.A., \& Porteus, E.L. (2001). Selling to the newsvendor: An analysis of price-only contracts. Manufacturing \& service operations management, 3(4), 293-305. http://dx.doi.org/10.1287/msom.3.4.293.9971

Li, Y., Wei, C., \& Cai, X. (2012). Optimal pricing and order policies with B2B product returns for fashion products. International Journal of Production Economics, 135(2), 637-646. http://dx.doi.org/10.1016/j.ijpe.2011.05.004 
Linh, C.T., \& Hong, Y. (2009). Channel coordination through a revenue sharing contract in a two-period newsboy problem. European Journal of Operational Research, 198(3), 822-829. http://dx.doi.org/10.1016/j.ejor.2008.10.019

Liu, Z., \& Nagurney, A. (2011). Supply chain outsourcing under exchange rate risk and competition. Omega, 39(5), 539-549. http://dx.doi.org/10.1016/j.omega.2010.11.003

Mortimer, J.H. (2002). The effects of revenue-sharing contracts on welfare in vertically-separated markets: evidence from the video rental industry. Harvard University. http://www.chicagobooth.edu/research/workshops/AppliedEcon/archive/WebArchive2001200 2/mortimer.pdf

Padmanabhan, V., \& Png, I.P. (1995). Returns policies: Make money by making good. Sloan Management Review, 37, 65-65.

Padmanabhan, V., \& Png, I.P. (1997). Manufacturer's return policies and retail competition. Marketing Science, 16(1), 81-94. http://dx.doi.org/10.1287/mksc.16.1.81

Tang, S.Y., \& Kouvelis, P. (2014). Pay-Back-Revenue-Sharing Contract in Coordinating Supply Chains with Random Yield. Production and Operations Management. http://dx.doi.org/10.1111/poms.12240

Wang, Y., \& Zipkin, P. (2009). Agents' incentives under buy-back contracts in a two-stage supply chain. International Journal of Production Economics, 120(2), 525-539. http://dx.doi.org/10.1016/j.ijpe.2009.04.008

Yao, Z., Leung, S.C., \& Lai, K.K. (2008). Analysis of the impact of price-sensitivity factors on the returns policy in coordinating supply chain. European Journal of Operational Research, 187(1), 275-282. http://dx.doi.org/10.1016/j.ejor.2007.03.025 


\section{Appendix}

Proof of Proposition 2.1. In the decentralized decision-making model, the supplier first announce the wholesale price $w$, then the retailer choose an optimal order quantity after the observation of $w$. Based on Equation 2, the optimal wholesale price is:

$$
w=\frac{p \bar{F}(q)}{x_{0}}
$$

In the equation above, $\bar{F}(q)=1-F(q)$. Based on the optimal wholesale price, the optimal order quantity can be derived as follows:

$$
p \bar{F}\left(q^{*}\right)\left(1-\frac{q^{*} f\left(q^{*}\right)}{\bar{F}\left(q^{*}\right)}\right)-c x_{0}=0
$$

In the centralized decision-making model, the retailer will choose the optimal order quantity based on the product cost instead of the wholesale price. Let $q_{o}^{*}$ denote the optimal order quantity in the centralized decision-making. It is easy to know that $q_{o}^{*}$ is:

$$
q_{o}^{*}=F^{-1}\left(\frac{p-c x_{0}}{p}\right)
$$

Proof of Lemma 1. Based on the definitions of $\Gamma$ and $X, E \Gamma$ can be written as:

$$
E \Gamma=\int_{A}^{B} x g(x) d x \int_{A}^{B} \frac{1}{x} g(x) d x \geq \int_{A}^{B} \frac{x}{x} g(x) d x=1
$$

The necessary and sufficient conditions for $E \Gamma=1$ is that there is no exchange rate fluctuation in this supply chain. Based on former assumption and the above equation, the inequation $E \Gamma>1$ holds.

As we assumed before, at the beginning of the sale season, the value of $x$ is $x_{0}$; at the end of the sale season, the expected value of $x$ will be $E$.When the currency of country 2 in the relatively appreciation, the inequation $E>x_{0}$ holds; when the currency of country 2 in the relatively depreciating, the inequation $E<x_{0}$ holds. Therefore, the relationship between $\Gamma x_{0}$ and 1 depends on the distribution of exchange rate when the currency of country 2 in the relatively appreciation; the inequation $\Gamma x_{0}>1$ holds when the currency of country 2 in the relatively depreciation.

Proof of Proposition 3.1. Based on Equation 4, the supplier's strategy is to find an optimal combination of the wholesale price and the buy-back price. And the retailer's strategy is to choose an optimal order quantity based on the observation of the wholesale price and the buy- 
back price. When the payment is settled in the currency of country 1 , the optimal wholesale price and the optimal buy-back price can be derived as follows:

$$
\frac{w_{b 1}-b_{b 1}+\frac{b_{b 1}\left(p-w_{b 1} x_{0}\right)\left(1-\Gamma x_{0}\right)}{p}}{c}=\frac{p-b_{b 1} x_{0}}{p}
$$

Based on the research of Cachon [3], let $\lambda_{b 1}$ denote the retailer's share of the global supply chain's profit, and then $\lambda_{b 1}$ satisfies:

$$
\left\{\begin{array}{l}
p-b_{b 1} x_{0}=\lambda_{b 1} p \\
w_{b 1}-b_{b 1}+\frac{b_{b 1}\left(p-w_{b 1} x_{0}\right)\left(1-\Gamma x_{0}\right)}{p}=\lambda_{b 1} c
\end{array}\right.
$$

Put above equation into Equation 4. Therefore, $E\left(\Pi_{r b 1}\right)$ and $E\left(\Pi_{s b 1}\right)$ can be written as follows, respectively:

$$
\left\{\begin{array}{l}
E\left(\Pi_{r b 1}\right)=\lambda_{b 1} \Pi_{b 1}-\frac{\left(1-\lambda_{b 1}\right) \lambda_{b 1} q_{b 1}\left(p-c x_{0}\right)\left(\Gamma x_{0}-1\right)}{\lambda_{b 1}+\left(1-\lambda_{b 1}\right) \Gamma x_{0}} \\
E\left(\Pi_{s b 1}\right)=\frac{\left(1-\lambda_{b 1}\right) \Pi_{b 1}}{x_{0}}+\frac{\left(1-\lambda_{b 1}\right)\left(\Gamma x_{0}-1\right)}{x_{0}}\left(\frac{\lambda_{b 1} q_{b 1}\left(p-c x_{0}\right)}{\lambda_{b 1}+\left(1-\lambda_{b 1}\right) \Gamma x_{0}}-p I\left(q_{b 1}\right)\right)
\end{array}\right.
$$

In which $\Pi_{b 1}=p S\left(q_{b 1}\right)-c q_{b 1} x_{0}$. The above equations show that, the optimal order quantity of this supply chain depends on $\Gamma$. Based on Proposition 2.1, it is clear to see that the optimal order quantity will diverge from the optimal order quantity of the centralized decision-making model.

Proof of Proposition 3.2. Based on Equation 5 and the node-enterprises' decision-making process, the optimal wholesale price and the optimal buy-back price can be derived as follows:

$$
\frac{w_{b 2}-b_{b 2}+\frac{b_{b 2}\left(w_{b 2}-c\right)\left(x_{0}-E\right)}{p}}{c}=\frac{p-b_{b 2} x_{0}}{p}
$$

Let $\lambda_{b 2}$ denote the retailer's share of the global supply chain's profit, and then $\lambda_{b 2}$ satisfies:

$$
\left\{\begin{array}{l}
p-b_{b 2} x_{0}=\lambda_{b 2} p \\
w_{b 2}-b_{b 2}+\frac{b_{b 2}\left(w_{b 2}-c\right)\left(x_{0}-E\right)}{p}=\lambda_{b 2} c
\end{array}\right.
$$


Put above equation into Equation 5. Therefore, $E\left(\Pi_{r b 2}\right)$ and $E\left(\Pi_{s b 2}\right)$ can be written as follows:

$$
\left\{\begin{array}{l}
E\left(\Pi_{r b 2}\right)=\lambda_{b 2} \Pi_{b 2}+\frac{b_{b 2}\left(w_{b 2}-c\right)\left(x_{0}-E\right)}{p} x_{0} q_{b 2}-b_{b 2} I\left(q_{b 2}\right)\left(x_{0}-E\right) \\
E\left(\Pi_{s b 2}\right)=\left(1-\lambda_{b 2}\right) \frac{\Pi_{b 2}}{x_{0}}-\frac{b_{b 2}\left(w_{b 2}-c\right)\left(x_{0}-E\right) q_{b 2}}{p}
\end{array}\right.
$$

In which $\Pi_{b 2}=p S\left(q_{b 2}\right)-c q_{b 2} x_{0}$. The above equations show that, the optimal order quantity of this supply chain depends on $E$. Based on Proposition 2.1, it is clear to see that the optimal order quantity will diverge from the optimal order quantity of the centralized decision-making model.

Proof of Proposition 4.1. Based on Equation 6, the retailer's reaction function is:

$$
p \varphi\left(1-F\left(q_{r 1}\right)\right)-w_{r 1} x_{0}=0
$$

And the supplier's strategy is to announce a wholesale price to maximize its expected profit. So the optimal wholesale price can be derived as follows:

$$
w_{r 1}-c+p(1-\varphi) \Gamma\left(1-F\left(q_{r 1}\right)\right)=0
$$

Thus, the optimal $\varphi$ and $w_{r 1}$ can be derived as follows:

$$
w_{r 1}=\frac{\varphi c}{1+(1-\varphi)\left(\Gamma x_{0}-1\right)}
$$

Put above equation into Equation 6, the node-enterprises' expected profits can be written as follows, respectively:

$$
\left\{\begin{array}{l}
E\left(\Pi_{r r 1}\right)=\varphi \Pi_{r 1}+\frac{q_{r 1} \varphi c x_{0}(1-\varphi)\left(\Gamma x_{0}-1\right)}{1+(1-\varphi)\left(\Gamma x_{0}-1\right)} \\
E\left(\Pi_{s r 1}\right)=\frac{(1-\varphi) \Pi_{r 1}}{x_{0}}+\frac{p S\left(q_{r 1}\right)(1-\varphi)\left(\Gamma x_{0}-1\right)}{x_{0}}-\frac{q_{r 1} \varphi c(1-\varphi)\left(\Gamma x_{0}-1\right)}{1+(1-\varphi)\left(\Gamma x_{0}-1\right)}
\end{array}\right.
$$

In which $\Pi_{r 1}=p S\left(q_{r 1}\right)-c q_{r 1} x_{0}$.

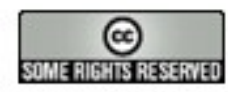

Article's contents are provided on an Attribution-Non Commercial 3.0 Creative commons license. Readers are allowed to copy, distribute and communicate article's contents, provided the author's and Journal of Industrial Engineering and Management's names are included. It must not be used for commercial purposes. To see the complete license contents, please visit http://creativecommons.org/licenses/by-nc/3.0/. 